\title{
Common criteria for usability review
}

\author{
Victor Nassar ${ }^{\mathrm{a}^{*}}$ \\ a Design Deparment, Federal University of Paraná, Ed. Dom Pedro , Rua General Carneiro, 460, CEP 80060- \\ 150, Curitiba-PR, Brazil.
}

\begin{abstract}
The propose of this paper is to present a literature review, in a grouping of common criteria for usability approaches of Bastien and Scapin (1993), Nielsen (1994), Shnneiderman(1998), Dix et al (1998), Preece et al (2005) and ISO 9241-110 (2006). After establishment of prerequisites for knowledge of the general characteristics of the users who will use the system, are defined and explained the criteria in common: consistency, user control, ease of learning, flexibility, errors management, reduction of excess and visibility system status. Although there is no determination as to which criteria should be considered when developing an interface and each author presents some specificity in their approach, it is observed that there is equivalence in the measures adopted usability.
\end{abstract}

Keywords: evaluation measures; interaction human-computer; interface design; users prerequisites.

\section{Introduction}

This paper intends to establish a compilation of criteria for evaluating the usability of different authors. However, it is not intended to replace the definitions of the authors, but offer to the reader an overview that shows the criteria in common. This work has been a starting point for the subsequent construction of a model of usability evaluation.

In order to try to measure the usability of a system, several authors present a set of criteria considered essential in the development of an interface. There are, for example, the criteria of Bastien and Scapin ergonomic (1993), the eight Golden Rules of Shneiderman (1998), the goals of Preece, Rogers and Sharp (2005), the ten fundamental heuristics from Nielsen (1994), and others.

In general, there are similar definitions about the concept of usability and criteria established to ensure the usability of a system. Thus, it is justified by this article provide the reader an overview and a reference on the criteria adopted by different authors, which despite having different names, can fit the same category.

It is known that the same interface can have different usability features, depending on the context of use and type of users who will use them. Thus, the issues that are adopted first attempt to establish the general characteristics of the users who will use the interface, such as what level of understanding users have on how to interact with the machine, what users want with the interface or why they need to use it, the context in which the user is inserted.

After discussion on the issues used as a prerequisite for the application of usability, it performed the synthesis of the criteria for Bastien and Scapin (1993), Nielsen (1994), Shnneiderman (1998), Dix et al (1998), Preece et al (2005) and ISO 9241-110 (2006). The following criteria were analyzed in common: consistency, user control, ease of learning, flexibility, errors management, reduction of excess and visibility of system status. In order to achieve a better organization and display, the seven usability criteria that are common to the authors and were previously presented will be listed in a table. Beside each common criterion, there is the equivalent criterion of each author.

\section{Usability}

Usability is one of the areas involved in developing a user experience in a system. Nielsen (2003) defines usability as a quality attribute that determines

*Email: victornassar@gmail.com 
how the interface is easy to use by users. Following the definition of Nielsen (2003), understanding that a system that is easy to use is one has good usability, it can be lead to believe that a good usability can be crucial to provide a good user experience.

However, depending on the context, it may have a good user experience without good usability, since several other areas such as aesthetics and interactivity are related. A good user experience is determined in accordance with the objectives for the system. Nevertheless, the adoption of good usability in a system can be decisive for a good user experience. This is one of the goals of this system, for example, ease of understanding for use by users.

This ease of use is only one of the characteristics commonly found in the authors' definitions for usability. Generally, the ISO 9241-11 (1998:3) defines usability as "the extent to which a product can be used by specified users to achieve specified goals with effectiveness, efficiency and satisfaction in a specified context of use". Thus, the relationship between the elements taking part in the process of usability can be seen in the following figure, proposed by ISO 9241-11 (1998) and defined as a usability framework.

Figure 1 Usability framework.

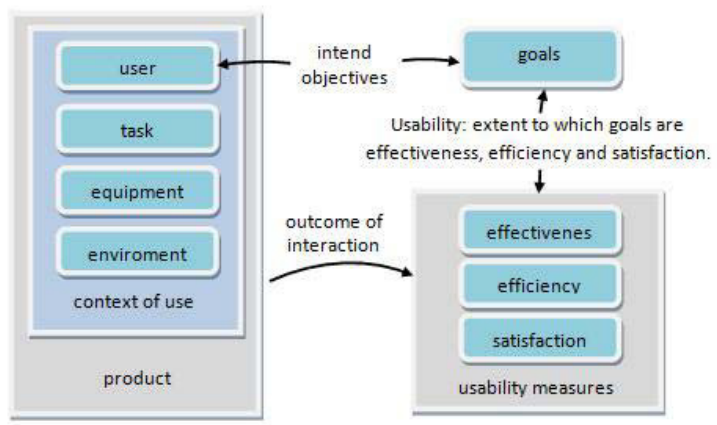

Therefore, the ISO 9241-11 (1998) believes that a system (product) has a good usability (intend objectives $=$ outcome of interaction) when users reach the goals with completeness (effectiveness), providing little effort (efficiency) and satisfied with the outcome (satisfaction). However, a good usability also depends on the context in which the user will work and can be influenced by the type of equipment used, the environment in which the user is, the type of task and has its own characteristics from each user.

In relation to these influences exerted on the usability of a system, Cybis, Betiol and Faust (2007:15) also warn that although the usability is a "quality that characterizes the use of programs and applications," it also "depends on an agreement between the characteristics of their interfaces and the characteristics of its users to seek specific goals for use in certain situations." Cybis, Betiol and Faust (2007) argue that the same interface can have different characteristics usability depending on the type of user who will use it. An expert user can gain satisfaction during use; novice user may already have complications and failure to attain the goals. Usability can also be changed as the ability of computers (whether slow or fast) or according to frequency of use.

\section{Users prerequisites}

It is observed that the usability depends not only on the characteristics of the system. Therefore, it is important to identify the profile of the people who will use the interface, the behavior of users in relation to the tasks they should perform to achieve the objectives, as well as the context in which such use is inserted. It is expected that in applying the usability of a website which the users' interface is intended, in a specific context, is able to perform all tasks assigned by the system efficiently, effectively reaching the objectives, generating satisfaction in using.

As prerequisites, and adopting a stance of usercentered design, it should first try to understand the general characteristics of the users who will use the interface:

- What level of understanding users have about the interaction with the machine, if they are used to interfaces or have little use experience. If they have an easy or a potential slow pace on learning. For example, if young people are accustomed to deal with digital equipment or elderly struggling to interact with these devices.

- What do users want with the interface or why do they need to use it? For example, if the navigation has a specific goal to users, as only searching for information without wasting time or also as entertainment.

- What is the context in which the user is inserted? What are the possible conditions of use for users, the equipment may be used, the Internet connection speeds, the social and technical environments, and others.

It is first important to know what the prerequisites for the use, so that the compilation of the common criteria of usability is situated in the same general context of user experience. 


\section{Common criteria for usability}

In general, there are similar definitions of the concept of usability and items needed to ensure usability in a system. In addition to the recommendations of its own ISO 9241-11 (1998) and Cybis, Betiol and Faust (2007), there is, for example, the ergonomic criteria of Bastien and Scapin (1993), the eight Golden Rules of Shneiderman (1998), the goals of Preece, Rogers and Sharp (2005), the ten fundamental heuristics of Nielsen (1994), and others. Although they sometimes have different names, some criteria may have the same meaning. The change of names can cause confusion or suggest a different concept for the same criterion.

a) Consistency: It is expected that the system shows consistency in their actions, so that the user can get familiar with the commands, without spending time learning new roles. The adoption of standards for color, typography, positioning, page titles, among others, helps prevent a complication in the navigation and user interface reside on the website. (Uniformity and Consistency of Bastien and Scapin, 1993; Consistency and standards Nielsen, 1994; Predictability, Capacity of Synthesis and Capacity of Generalization of Dix et al, 1998; Consistency of Shneiderman, 1998; Efficient use of Preece et al, 2005; Conformity to user expectations of ISO 9241110, 2006).

b) User control: it is expected that the system offers the user control options for the interface. It is expected that the system offers, for example, the ability to go back or forward pages, undo, or cancel operations, restart, pause, resume or terminate the activities. By offering certain freedom to the user, you can allow him to escape from making mistakes or even if the system make itself a mistake. (Explicit control of Bastien and Scapin, 1993; Freedom and User control of Nielsen, 1994; Initiative Dialog of Dix et al, 1998; Reversal of shares and User control of Shneiderman, 1998; Efficient use of Preece et al, 2005; User Control and Ease of individualization of ISO 9241-110, 2006).

c) Ease of learning: the system must be easy to learn, both for the user quickly start the use, to easily remind the usage, even after an idle period. In order to achieve this, it is expected that the system has tasks that meet the users' habits. Thus, it avoids using technical terms, elements or icons that are not familiar to users, to minimize misinterpretation and could lead you astray. (Compatibility of Bastien and Scapin, 1993; System compatibility with the real world, Ra- ther than recognition memory of Nielsen, 1994; Familiarity and Observability of Dix et al, 1998; Easy to learn, easy to remember how to use and Efficiency in the use of Preece et al, 2005).

d) Flexibility: it is expected that the system offers different ways of performing the same task, so the user can choose which adapts better to their authority or context. This flexibility may occur through shortcut keys, different menu options, or even icons for interface customization, for example. (Adaptability of Bastien and Scapin, 1993; Flexibility and Efficiency in the use of Nielsen, 1994; Capacity of Migration, Replacement and Configuration, and the Compliance task of Dix et al, 1998; Shortcut to experienced users of Shneiderman, 1998; Good value and efficient use of Preece et al, 2005; Adaptation and Adjustment to the task for learning of ISO 9241-110, 2006).

e) Erros management: it is expected that the system has mechanisms for preventing, detecting and correcting errors, reducing the risk of the user to perform unwanted actions, and alerts the user of an error and provide ways to recover. It is also expected that the system provides mechanisms to help and to assist the user in performing the tasks, avoiding in this way possible errors. (Erros management of Bastien and Scapin, 1993; Prevention of errors, User help in the recognition, Diagnosis and Correction of errors and Support and Documentation of Nielsen, 1994; Recoverability of Dix et al, 1998; Reversal of actions of Shneiderman, 1998; Efficiency in the use and safety in the use of Preece et al, 2005; Error tolerance of ISO 9241-110, 2006).

f) Reduction of excess: it is expected the system to avoid the inclusion of irrelevant content or the user does not need much because it can reduce his focus on the really necessary or useful information. Likewise, it is also expected that the system has the fewest possible actions to perform a task, avoiding complex tasks that can hinder learning and increase the chance of errors. (Workload Bastien and Scapin, 1993; Minimalist design and Recognition rather than memorization of Nielsen, 1994; Ability to synthesis, Generalization and Replacement of Dix et al, 1998; Low load of memorization of Shneiderman, 1998; Efficiency in the use of Preece et al, 2005).

g) Visibility of system status: It is expected that the system is able to guide the user, presenting information so that this user interface to locate and identify the items and possible actions. For example, if the time to perform a task by the system will not be instantaneous, the system should keep the user informed of waiting. By providing both the expected 
feedback, the completion, with clear and objective answers, the system can offer the user the assurance that it is operating within a normal range provided and can facilitate the user to maintain or regain focus on the dialogue. (User guidance of Bastien and Scapin, 1993; Visibility of system status of Nielsen, 1994; Responsiveness of Dix et al, 1998; Feedback informative and dialogues that indicate the end of action of Shneiderman, 1998; Efficiency in the use of Preece et al, 2005; Self-description of ISO 9241-110, 2006).

In order to better organization and display, the seven usability criteria that are common to the authors and were presented and explained above will be listed in a next table. Beside each common criterion is the criterion equivalent to each author.

Table 1

Compilation of common criteria for usability

\begin{tabular}{|c|c|}
\hline Common criteria & Names given by authors \\
\hline Consistency & $\begin{array}{l}\text { - Uniformity and Consistency of Bastien and Scapin, 1993; } \\
\text { - Consistency and standards Nielsen, 1994; } \\
\text { - Predictability, Capacity of Synthesis and Capacity of Generalization of Dix et al, 1998; } \\
\text { - Consistency of Shneiderman, 1998; } \\
\text { - Efficient use of Preece et al, 2005; } \\
\text { - Conformity to user expectations of ISO 9241-110, } 2006 \text {. }\end{array}$ \\
\hline User control & $\begin{array}{l}\text { - Explicit control of Bastien and Scapin, 1993; } \\
\text { - Freedom and User control of Nielsen, 1994; } \\
\text { - Initiative Dialog of Dix et al, 1998; } \\
\text { - Reversal of shares and User control of Shneiderman, 1998; } \\
\text { - Efficient use of Preece et al, 2005; } \\
\text { - User Control and Ease of individualization of ISO 9241-110, } 2006 .\end{array}$ \\
\hline Ease of learning & $\begin{array}{l}\text { - Compatibility of Bastien and Scapin, 1993; } \\
\text { - System compatibility with the real world, Rather than recognition memory of Nielsen, 1994; } \\
\text { - Familiarity and Observability of Dix et al, 1998; } \\
\text { - Easy to learn, easy to remember how to use and Efficiency in the use of Preece et al, } 2005 \text {. }\end{array}$ \\
\hline Flexibility & $\begin{array}{l}\text { - Adaptability of Bastien and Scapin, 1993; } \\
\text { - Flexibility and Efficiency in the use of Nielsen, 1994; } \\
\text { - Capacity of Migration, Replacement and Configuration, and the Compliance task of Dix et al, 1998; } \\
\text { - Shortcut to experienced users of Shneiderman, 1998; } \\
\text { - Good value and Efficient use of Preece et al, 2005; } \\
\text { - Adaptation and Adjustment to the task for learning of ISO 9241-110, } 2006 \text {. }\end{array}$ \\
\hline Errors management & $\begin{array}{l}\text { - Erros management of Bastien and Scapin, 1993; } \\
\text { - User help in the recognition, Prevention, Diagnosis and Correction of errors and Support and Documentation } \\
\text { of Nielsen, 1994; } \\
\text { - Recoverability of Dix et al, 1998; } \\
\text { - Reversal of actions of Shneiderman, 1998; } \\
\text { - Efficiency in the use and safety in the use of Preece et al, 2005; } \\
\text { - Error tolerance of ISO 9241-110, 2006. }\end{array}$ \\
\hline Reduction of excess & $\begin{array}{l}\text { - Workload Bastien and Scapin, 1993; } \\
\text { - Minimalist design and Recognition rather than memorization of Nielsen, 1994; } \\
\text { - Ability to synthesis, Generalization and Replacement of Dix et al, 1998; } \\
\text { - Low load of memorization of Shneiderman, 1998; } \\
\text { - Efficiency in the use of Preece et al, 2005. }\end{array}$ \\
\hline Visibility system status & $\begin{array}{l}\text { - User guidance of Bastien and Scapin, 1993; } \\
\text { - Visibility of system status of Nielsen, 1994; } \\
\text { - Responsiveness of Dix et al, 1998; } \\
\text { - Feedback informative and dialogues that indicate the end of action of Shneiderman, 1998; } \\
\text { - Efficiency in the use of Preece et al, 2005; } \\
\text { - Self-description of ISO 9241-110, 2006. }\end{array}$ \\
\hline
\end{tabular}

\section{Discussion}

In addressing the usability of a system, each author offers his own emphasis. The focus of analysis can vary according to the project chosen by the prospect, with a task being handled more rigidly than others, for example. Well, it is frivolous attempt to choose a set of criteria and adopt it as a universal standard, 
since there is a specific selection or something that is wrong or incomplete. Sometimes it is even necessary to use different approaches to evaluate the usability of an interface in order to try to find as many problems as possible. Similarly, each interface has its own peculiarities, which require an analysis model itself.

Thus, this paper intends only to get to know some criteria of usability and find them on common ground. The compilation of multiple criteria in common criteria may help in understanding the general sense. For example, a common standard for the meaning of Consistency, there are "Conformity to user expectations" or "Capacity of Generalization" that, although they have very specific definitions, can fit in the same general sense of providing a standard for the interface elements.

The variety of names established by the authors also creates a difficulty in determining a common name to group all the criteria. Furthermore, by creating one more name, even to set up common criteria also can generate the same consternation over a different name for the criterion. Thus, for the name of the common criteria, we chose to use a name which has been preferentially used by any author and to convey a comprehensive sense. It is understood, for example, that "User Control" has a broader meaning than "Reversal of shares", "Initiative Dialog" or "Ease of individualization."

Another difficulty in establishing a common standard is the fact that the criteria adopted by the authors may represent a very specific quality of common criteria. Bastien and Scapin (1993), for example, established several key criteria, but each with other specific criteria subdivisions. The criterion "Adaptability" of Bastien and Scapin (1993), have subcriteria "Flexibility" and "User Experience".

The case of the criterion adopted by the author is broader than the common criteria established in this work. Preece et al (1998) establishes a broad criterion called "Efficient of use" which can have different applications in the interface approach. If the common criteria established herein are intended to efficiently use interface, this criterion of Preece et al (1998) may be present in all of them.

\section{Conclusion}

This paper intended to provide a review of literature, an approach that established a compilation of usability criteria. Although each author has their own specific approach to usability and denominations, it was observed that there is great similarity between the definitions and terms, making them capable of grouping.

It is expected that this research has contributed to a better understanding of the criteria for evaluation of the usability of interfaces and better association of the different terms used by the authors. It is also hoped that this paper assists students in applying the design criteria of usability.

As future studies, it is proposed to carry out synthesis of definitions from other areas of HumanComputer Interaction, Interactivity and UserCentered Design and in order to foster discussion and encourage the application of common criteria in their respective areas. Later this compilation will be tested and evaluated to verify its use as a general model of usability criteria.

\section{References}

[1] C. Bastien, and D. Scapin. Ergonomic criteria for the evaluation of human-computer interfaces. Tech. Rep. n.156. Rocquencourt, France: Institut National de Recherche en Informatique et en Automatique. 1993. Apud: LABIUTIL. Laboratório de Utilizabilidade. Critérios Ergonômicos para Avaliação de Interfaces Homem - Computador. Universidade Federal de Santa Catarina. Disponível em: $<$ http://www.labiutil.inf.ufsc.br/CriteriosErgonomicos/Abertur a.html> Acesso: 05 mai. 2011.

[2] W. de A. Cybis, A. H. Betiol and R. Faust. Ergonomia e usabilidade: conhecimentos, métodos e aplicações. São Paulo: Novatec Editora, 2007.

[3] A. Dix, J. Finlay, G. Abowd and R. Beale. Human-Computer Interaction. 3 ed. Prentice-Hall International, 2004.

[4] ISO 9241. Ergonomic of human-system interaction. Part 110 Dialogue principles; Draft International Standard ISO, 2006.

[5] ISO 9241-11. 1998. Disponível em: $<$ http://www.inf.ufsc.br/ cybis/pg2003/iso9241-11F2.pdf> Acesso em: 05 mai. 2011.

[6] J. Nielsen. Heuristic evaluation. In: J. Nielsen and, R. L. Mack (Eds.), Usability Inspection Methods, John Wiley \& Sons, New York, NY. 1994. Disponível em: $<$ http://www.useit.com/papers/heuristics/heuristic_list.html $>$. Acesso: 05 mai. 2011.

[7] Usability 101: Introduction to usability. Useit.com. 2003. Disponível em: <http://www.useit.com/alertbox/20030825.html>. Acesso: 05 may. 2011.

[8] J. Preece, Y. Rogers and H. Sharp. Design de interação: além da interação humano-computador. Porto Alegre: Bookman, 2005.

[9] B. Shneiderman, Designing the user interface: strategies for effective human-computer-interaction. 3rd ed Reading: Addison Wesley Longman, 1998. 